\title{
Use of closured open pit and underground coal mines for energy generation: Application to the Asturias Central Coal Basin (Spain)
}

\author{
Javier Menéndez ${ }^{1}$ and Jorge Loredo ${ }^{2}$ \\ ${ }^{1}$ HUNASER ENERGY, 33005 Oviedo, Spain \\ ${ }^{2}$ UNIVERSITY OF OVIEDO, Mining Exploitation Department, 33004 Oviedo, Spain
}

\begin{abstract}
The idea to reducing the dependency of nuclear and fossil energy sources has risen in Spain, then, the use of closured coal mines for energy generation is thus in the political interest, and by 2020 it is intended that the country produces $20 \%$ of its energy from renewable sources, therefore replacing the energy based on fossil fuels. New studies on the framework of a circular economy have led to found new possibilities for closured coal mines in historical mine districts and mine water can be considered as a potential resource, converting mining exploitations into storage and production facilities of renewable energy and generating new economic activities in the mining regions. Abandoned and flooded mines constitute artificial karst type aquifers, and these created underground reservoirs can be economically managed to supply geothermal energy to villages around the shafts. This potential application of mine water, profitable in both economic and environmental terms, could contribute to improve economic and social conditions of traditional mining areas in gradual decline. On the other hand, the restored lands can be used for the production of biofuels through repopulation with fast-growing energy crops and high planting densities. This paper analyses the uses of mine water for energy generation both as geothermal resource and through pumped storage between an underground and a surface reservoir, furthermore the supply of productive restoration for biomass production in closured coal open pits is considered, in relation to their potential application to the closured coal mines from the Asturias Central Coal basin in Northern Spain.
\end{abstract}

\section{Introduction}

The contribution of renewable energies to the world's total energy demand has increased particularly during the last two decades, and they will continue gaining market share. The idea to reducing the dependency of nuclear and fossil energy sources has risen in Spain, then, the promotion of renewables is thus in the political interest, and by 2020 it is intended that the country produces $20 \%$ of its energy from renewable sources, therefore replacing the energy based on fossil fuels. This paper analyses the potential use of closured coal mines for energy generation.

Even though it is regarded as a crucial economic activity worldwide, mining has a significant negative impact on environment. Due to its nature, especially opencast mining inevitably leads to serious degradation on ecological and aesthetic values of the landscape. When the extraction of reserve is over, the altered landscape has to be reclaimed in order to relieve the damaging effects of opencast mining and restore the landscape and its immediate surroundings. Mining operations alter the natural flow of groundwater, and the mining voids, together with the spaces created due to the fracturing induced by mining, can be filled up with water, once the mines are closed and inundated, materializing then a new aquifer or "mining reservoir". Flooded mines constitute artificial karst type aquifers.

New studies on the framework of a circular economy have led to found new possibilities for mine water which can be considered as a potential resource, converting mining exploitations into storage and production facilities of renewable energy and generating new economic activities in the mining regions. Then, mine water, either coming from the pumps or from the stage rebound after flooding during the closure period, could be used with economic and social benefits for energy generation.

\section{The Asturian Central Coal Basin (ACCB) in northern Spain}

The Asturian Central Coal Basin (ACCB), which has been exploited from the end of the eighteen century and the lst mine in operation wil be closured for the end of the present year. This coal mining district constitutes the main Spanish coal basin and it is characterized from a hydrogeological point of view by the presence of predominantly low porosity and permeability materials. Groundwater flow occurs mainly through mining voids, open fractures, and zones of decompression associated with coal mining. 
The Asturian Central Coal Basin (ACCB) is located in northern Spain. With an area of about $1400 \mathrm{~km}^{2}$, the ACCB is the largest carboniferous outcrop of the peninsula and the main Spanish coal mining district. This coal basin has been an exploited for more than 200 years, through open pit and underground mining, with indoor mining predominating in the last decades.

This potential application of mine water, profitable in both economic and environmental terms, could contribute to improve economic and social conditions of traditional mining areas in gradual decline.

\subsection{Potential for energy generation in closured underground mines}

When mining ends, one option is to abandon pumping, gradually flooding both the mine voids and the open pores; this 'groundwater rebound' [1] continues until potentiometric equilibrium is reached [2]. If the lithological units connected to any part of the flooded system intersect the surface at a level lower than that of the mouth of the mine shaft, water upwelling (a spring) will occur. If pumping is resumed such that its discharge is equal to the recharge, the water level can be stabilized throughout the ductwork of the new aquifer. The stored volume is then equivalent to that of the filled voids and an underground reservoir has been created. These created underground reservoirs can be economically managed to supply geothermal energy (mainly by means of heat pumps) and hydroelectricity by Pumped Storage Hydropower (PSH) projects with a Francis turbine-pump.

\subsubsection{Mine water as a geothermal resource}

One of the most important uses of mine water is the production of thermal energy for air conditioning of buildings. The temperature of water from the coal mining reservoirs in Europe is usually above $14^{\circ} \mathrm{C}$, so modern heat pumps using it as cold source are competitive, considering current prices of electricity and fuel [3]. Producing energy by means of heat pumps using mine water, compared to conventional systems using natural gas, in several applications, means economic savings above $70 \%$ and reductions of $\mathrm{CO}_{2}$ emissions between $20-40 \%$.

Heat pump technology has been around since 1852 when Lord Kelvin first developed the concept. In the 1940s, Robert Webber modified the concept using the ground as the source of heat. These ground source or geothermal heat pumps systems gained popularity in the 1960s and 1970s. Figure 1 shows a diagram of a heat pump system. In heating mode, the refrigerant in a cold liquid form gains heat from the outside source (air or ground) in a heat exchanger (evaporator), where it is converted into a cold vapor. In order for the heat pump to function properly, the liquid form of the refrigerant must be at a lower temperature than the outside heat source and the temperature of the heat source must be high enough to cause the refrigerant to evaporate (boil). After the liquid absorbs heat and is converted to a vapor, it is then compressed (requiring an input of electrical energy), converting it to a hot vapor. The hot vapor is sent to another heat exchanger (condenser). Here the hot vapour gives up the heat that was gained from the source in the evaporator and in the process is condensed to a hot liquid (The heat given up is what is used to heat the interior space). The hot liquid goes through an expansion valve where the drop in pressure converts it to a cold liquid and the process is repeated. In heating mode, the evaporator is placed in contact with the heat source.

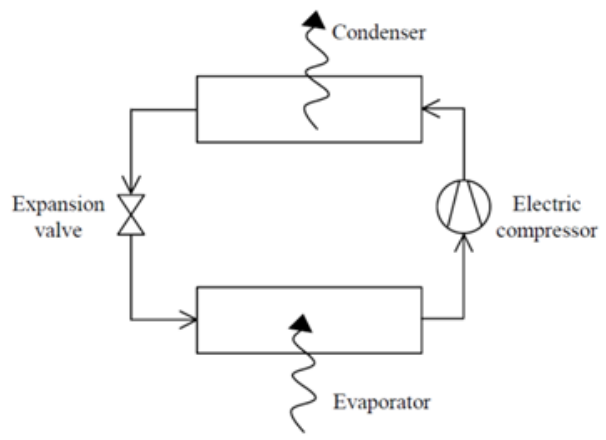

Figure 1. Schematic of head pump system

The heat pumps operate on electricity and the amount of heat generated divided by the amount of energy needed to operate the heat pump is known as the coefficient of performance (COP). The smaller the difference in temperature between the heat source and the heat sink (required temperature of space to be heated), the greater the COP of the heat pump system. For this reason, geothermal heat pumps have a greater efficiency than air-source heat pumps; the source/sink temperature (the earth) is closer to the desired room conditions than outdoor air temperatures.

In ACCB there is an important geothermal project in order to take advantage of the mine water supplying heating and cooling to the surrounding population and industrial districts by use of heat pump technologies.

The mine water stored in the mining reservoir has a considerable geothermal potential, given its temperature $\left(23{ }^{\circ} \mathrm{C}\right)$. It is non-acidic water, but is mineralized and hard, with quite high $\mathrm{Fe}$ and $\mathrm{Mn}$ content. For heat pump use, the heavy load of dissolved matter that coal mine waters commonly contain can cause problems by precipitating during heating and cooling, so effective (and expensive) water softener and descaling treatment may be necessary. The pumping is necessary to maintain the security level to avoid the flooding of the buildings that are located in the surroundings. Fig. 2 shows the temperature profile of the water stored in the closed coal mines. 


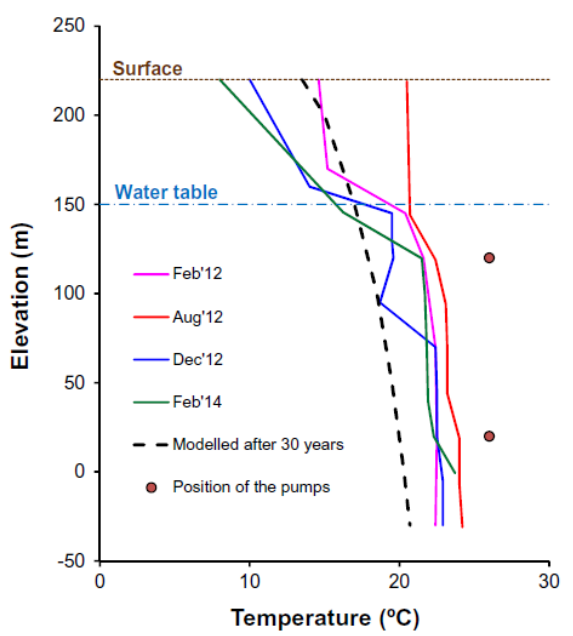

Figure 2. Mining reservoir temperature

Figure 3 shows the thermal energy produced from mine water for the air conditioning of a public building in the ACCB. It is an installation with an installed capacity of $3500 \mathrm{~kW}$ to supply cold and heat by means of heat pumps. The coefficient of performance (COP) is also shown, based on the electrical energy consumption of the heat pumps.

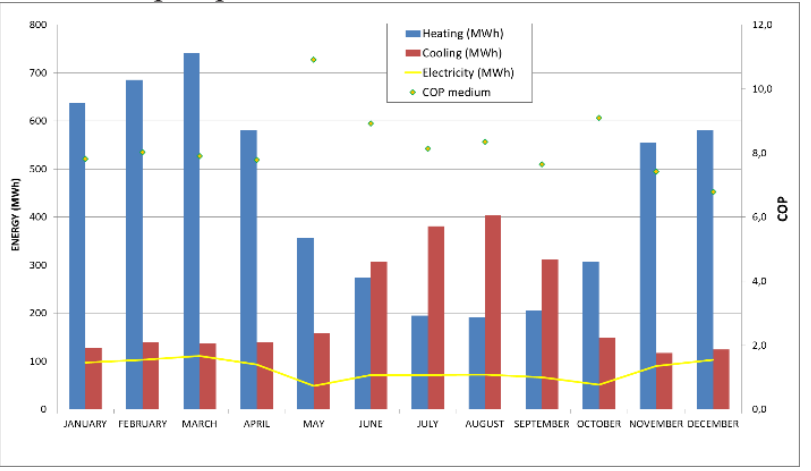

Figure 3. Thermal energy and coefficient of performance

\subsubsection{Pumped Storage Hydroelectricity}

The tunnel network of a mining facility has an unusual geometry for a storage system. Nevertheless, such storage volumes, combined with the depths at which some of these facilities are located and the high flows of mine water, can be sufficiently appealing to establish a Pumped Storage Hydropower (PSH) project with a Francis turbine-pump. The most relevant technical aspect is related to the storage structure for the lower reservoir. Fig. 4 shows the diagram of the hydroelectric power station. The upper reservoir is located outside and the lower reservoir is located inside the coal mine. The penstock would be built in the vertical shaft currently in existence.
COAL MINE POWER STATION HYDRO CIRCUIT

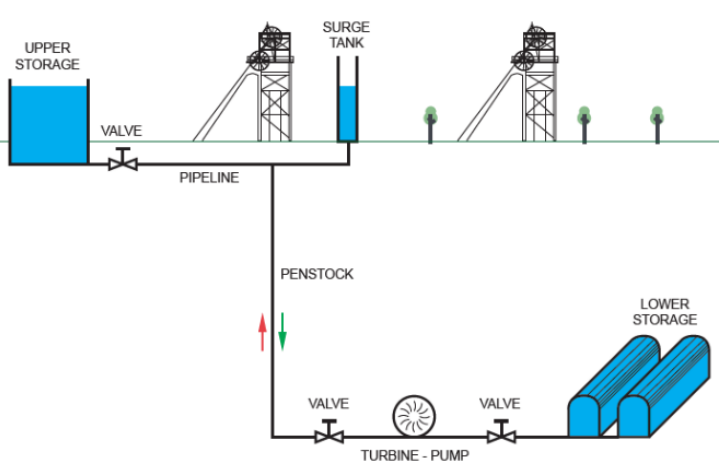

Figure 4. Coal mine hydro power station hydrocircuit

In a typical hydropower pumped storage project, the two reservoirs are located on the surface level. In contrast to a conventional PSHP plant, the upper reservoir of an Underground PSH power plant is the smaller problem, as it can basically be established on the surface. If an abandoned coal mine is envisaged, the (potentially large) area of the former mine may be available for use In the generally densely populated Asturian Central Coal Basin, at least small- and mediumsized storage reservoirs on the surface, may often be done without too much conflict with settlement areas. In the surroundings of the shafts there exist buildings that are protected as industrial heritage, which cannot be demolished.

Pumped hydroelectric energy storage is a large, mature, and commercial utility-scale technology currently used at many locations in the world. Pumped hydro employs off-peak electricity to pump water from a reservoir up to another reservoir at a higher elevation. When electricity is needed, water is released from the upper reservoir through a hydroelectric turbine into the lower reservoir to generate electricity.

Because most low-carbon electricity resources cannot flexibly adjust their output to match fluctuating power demands, there is an increasing need for bulk electricity storage due to increasing adoption of intermittent renewable energy. This technology can be the backbone of a reliable renewable electricity system.

The first idea of exploiting a disused mine as an underground reservoir dated from 1960 [4] and it was developed by several studies and technical reports but not accompanied by functioning pilot projects.

Mount Hope project, located in northern New Jersey was initially proposed in 1975 . It intended to use the facilities of an abandoned iron mine as a lower reservoir but it was never developed [5].

The feasibility of using some of the current coal mining facilities in the Ruhr region as lower reservoir for a pumped storage project has been currently analyzed by a group of five partners in Germany (University Duisburg Essen, Ruhr University Bochum, Rhine Ruhr Institute for Social Research and Political Consultancy RISP, RAG AG and DMT), supported by the European Union. 
Madlener and Specht presented an extremely interesting techno-economical analysis of the possible construction of underground PHES in Abandoned Coal Mines in the Ruhr area (Germany) [6]. Also in the Ruhr area, Alvarado et al presented a project of the possible construction of underground pumped storage power plant in Prosper Haniel mine in Bottrop (North-Rhine Wesphalia), using existing coal mine infrastructure [7].

This storage concept presents several advantages in comparison with conventional PHES, as for example the higher possibility of social acceptance and the larger number of potential sites. From a technical point of view, even though the construction of an underground storage reservoir is possible, the main limit is the need of competent rock, especially at reservoir depths.

An interesting unconventional pumped hydro project, proposed in Estonia (Project ENE 1001, 2010), is that of Muuga whose completion is expected in 2020. The peculiarity of this project is that it combines two different unconventional reservoirs: the sea as upper reservoir and underground chambers, resulting from granite excavations, as lower reservoir.

As regards the worldwide situation, with over 150 $\mathrm{GW}$, pumped hydro storage power plants represent around $99 \%$ of the world's electrical energy storage capacity. Currently Japan is the worldwide leader but China expands quickly and is expected to surpass Japan in 2018. In the future, as the renewable revolution gains momentum worldwide, hydropower looks to become an even more strategic player. The International Renewable Energy Agency (IRENA) conducted a technology roadmap (Remap) until 2030, and hydro capacity could increase up to $60 \%$, and the pumped hydro capacity could be doubled to $325 \mathrm{GW}$ from the $150 \mathrm{GW}$ installed in 2014. In the case of PSH plants (electrical energy), the conclusion for lower reservoirs is that the use of natural caverns is not possible; the artificial extraction of large cavities is technically demanding and financially expensive and thus does not seem to be very reasonable. In certain cases, existing drifts may at least be partly usable, e.g. after additional extension measures. However, for a general concept, considerations have to be based on the fact that the drifts for a rib-shaped storage system in the completion stage, would have to be built totally new. The power of the turbine depends on the flow and the net head. Fig. 5 shows the turbine power for a 6-hour full load cycle time. The power increases as the net head and the volume of water stored in the reservoirs increase.

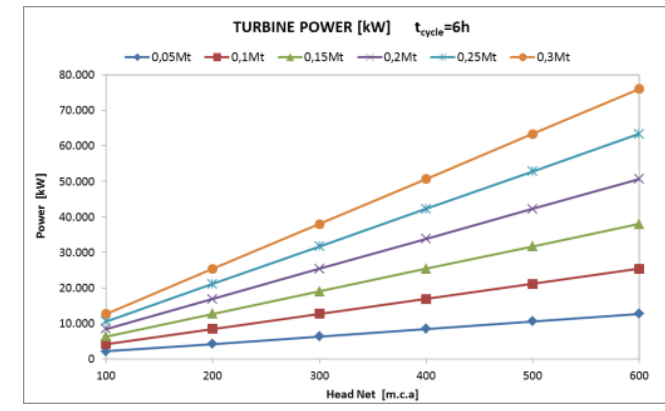

Figure 5. Turbine power (mass water - net head).

\subsection{Potential for energy generation in closured open pit mines}

During mining, significant amounts of soil and overburden have to be moved in order to access the coal seams beneath. In addition to the alteration in the water network, open-pit mining produces an important impact on the landscape, with visual impacts that must be restored to the end of the extractive activity. The restoration of affected lands is one of the main costs in open-pit mining. The first phase consists of the topographic restitution and the creation of a water drainage network that gives stability to the restored lands, avoiding erosion phenomena as a result of the circulation of runoff water. Later a layer of vegetal earth is added and it is finished with the hydroseeding of the lands. One of the main objectives of the restoration of lands affected by mining activity is the improvement of soil properties. The restoration can be approached from two points of view: environmental or protective restoration, and productive restoration. The environmental restoration is based on the repopulation with autochthonous arboreal species, with a slower growth, and a short-term economic benefit is not sought. On the other hand, through productive restoration, short-term restored land is valued by planting fast-growing energy crops. With this type of crops, much higher growth is achieved and by applying shorter cutting shifts, economic benefits are obtained from the first years using the biofuels obtained for the production of energy. Although the initial investment is higher in the case of productive restoration, the profitability is much higher than in the case of environmental restoration.

\subsubsection{Biomass production}

To reduce carbon dioxide emissions and the dependency on fossil fuels, the developed countries have begiun expanding renewable energy sources to meet energy mix policy goals for 2030 [8]. In 2008 research began on a restored surface of old mining operations in the Asturias Central Coal Basin, with an extension of 7.5 ha that were planted with forest energy crops using different clones of poplar, willow and birch. In total, 3 trials were carried out in different recovery areas. The study area is characterized by an oceanic climate, with average annual temperature of $13^{\circ} \mathrm{C}$ and an average annual precipitation of 1,115 mm, of which $345 \mathrm{~mm}$ falls during the growing season (May-September). Soil formation is at an early stage and the soil structure is still unstable. The steep slopes of the terrain minimize groundwater effects. The physiography of the plots was characterized by a mean slope of $19 \%$ and an elevation ranging from 508 to 597 $\mathrm{m}$ above sea level.

The first of the plantations was carried out in 2008, the factors to be studied in this first trial were: the type of clone, the density of plantation (two levels: 10,000 and 15,000 plants $\left.\mathrm{ha}^{-1}\right)$ and the treatment $(\mathrm{F} 0=\mathrm{Control}$ $\mathrm{F} 1=300 \mathrm{~kg} \mathrm{ha}^{-1}$ NPK 6:20:12 and $41 \mathrm{ha}^{-1}$ glyphosate, F2 $=600 \mathrm{~kg} \mathrm{ha}^{-1}$ NPK 6:20:12 and $41 \mathrm{ha}^{-1}$ glyphosate). 
The amounts of fertilizer to be used were chosen in view of the results obtained in the soil analysis prior to planting, taking into account the maximum amount of nitrogen allowed to be applied in vulnerable areas, which is $170 \mathrm{Mg} \mathrm{ha}^{-1}$.

\section{Conclusions}

The exploitation of coal in the Asturian Central Coal Basin in the North of Spain has occupied large areas of land that are currently being restored according to the current legislation.

Closed and inundated coal mines can constitute mining reservoirs which could be regulated and used for energy production, and for theses uses is essential to define the hydrogeological model, the water balance, and the volume of voids of the mining reservoir system previously the design of the project. Considering the pumping rates and the high COP values that can be reached for mine water in the ACCB, their energy use by means of water-water heat pumps for heating and cooling is optimal. The entire coal mining reservoirs in the ACCB involve a potential of energy supply higher than 250 thermal GWh year ${ }^{-1}$. Compared to conventional systems, economic savings and a reduction in $\mathrm{CO}_{2}$ emissions are achieved.

The implementation of an underground PSH project using coal mine facilities is an appealing option for energy storage, particularly in Spain where the underground mining is currently phased out, with an expected closure date at the end of 2018. PSH can provide many services to the power system, as flexibility of operation and speed to vary the power delivered to the grid. This aspect is fundamental to deal with the variations in production due to fortuitous failures in the thermal power plants and of any significant variations in the production of intermittent renewable power generation.

In relation to the restored lands, they can be used for the production of biofuels through repopulation with fast-growing energy crops and high planting densities. Certain poplar clones seem to grow rather well on a degraded mining soil with high $\mathrm{pH}$, even when slightly polluted with heavy metals. Organic fertilization was more efficient than the contribution of mineral fertilizer, also producing a continuous supply of nutrients over longer time and reducing the risk of washing.

In addition to the production of renewable energy and capture of $\mathrm{CO}_{2}$ emissions, these activities involve the generation of a new economic activity in abandoned land and the creation of jobs in depressed areas due to the closure of mining operations. These applications are encouraging and might be profitably extended to other minor coal mining basins in Asturias and other areas.

\section{References}

1. Henton MP. The problem of water table rebound alter mining activity and its effects on ground and surface water quality. In: van Duijvenbooden W, Glasbergen P, Van Lelyveld H (eds) Quality of Groundwater, Proceedings of the International Symposium Noordwijkerhout. Elsevier, The Netherlands, pp 111-116. (1981).

2. Younger PL, Banwart SA, Hedin RS. Mine Water. Hydrology, Pollution, Remediation. Kluwer Academic Publishers, Dordrecht, The Netherlands. (2002).

3. Ochsner K. Geothermal Heat Pumps. A guide to Planning \& Installing. Earthscan, London.

4. Harza, R.D. Hydro and pumped storage for peaking, Power Eng., vol. 64 (10), pp. 79-82. (1960).

5. Dames and Moore. An assessment of hydroelectric pumped storage. National hydroelectric power resources study. The U.S. Army Engineer Institute for water resources, pp. A-95-96. (1981).

6. Madlener, R., Specht, J.M. An Exploratory Economic Analysis of Underground Pumped Storage Hydro Power Plants in Abandoned Coal Mines, FCN Working Paper No. 2/2013. (2013).

7. Alvarado, R., Niemann, A., Wortberg, T. Underground pumped-storage hydroelectricity using existing coal mining infrastructure. In: E-proceedings of the 36th IAHR world congress, 28 June-3 July, 2015. The Netherlands: The Hague. (2015)

8. N. Agung, K. Itaoka, A. Chapman, N. Dinh Hoa, N. Yamakawa. Biomass energy in Japan: Current status and future potential. IJSGCE. Vol 6, no 2, pp 119126. (2017). 